\title{
Derrame pleural: uma complicação extra-intestinal da doença de Crohn"
}

\author{
Elie Fiss ${ }^{1}$, Flavio Steinwaurz ${ }^{2}$, Andrea Barranjard Vannucci ${ }^{3}$, CAmila de Menezes Succi $^{4}$
}

Paciente de 34 anos, portadora de doença de Crohn (DC) havia oito anos, foi atendida queixando-se de dor torácica e febre, sem manifestações gastrointestinais. Testes laboratoriais mostraram atividade inflamatória (VHS $=45 \mathrm{~mm}$, PCR positivo). O exame físico revelou derrame pleural na base do hemitórax esquerdo, confirmado pela radiografia de tórax. A análise do líquido pleural mostrou 100\% de linfócitos, com BAAR negativo. A biópsia pleural evidenciou granuloma não caseoso. Foi instituída terapia para tuberculose, sem sucesso, com regressão dos sintomas apenas após reintrodução de altas doses de corticosteróide, sugerindo atividade da DC como causa do derrame pleural.

(J Pneumol 2002;28(5):285-7)

\section{Pleural effusion: an extraintestinal complication of Crohn's disease}

A 34-year-old patient had had Crohn's disease (CD) for eight years; she was seen for complaints of thoracic pain and fever, without gastrointestinal manifestations. Initial laboratory exams were compatible with the presence of inflammatory activity (VHS $=45 \mathrm{~mm}$ for normal value of $20 \mathrm{~mm}$ and PCR+). The physical exam revealed signs of pleural effusion in the left hemithorax base, which was confirmed by thoracic RX. The pleural liquid analysis showed that the cells were 100\% of lymphocytes, with negative BAAR research. The pleural biopsy evidenced non caseous granuloma. Despite the tuberculosis treatment, the patient only got better when corticotherapy was introduced in high doses, suggesting the activity of $C D$ as the cause of the pleural effusion.

This case establishes a connection between activity of $C D$ and manifestations of lung disease.

Descritores - Doença de Crohn. Pleura. Derrame pleural. Corticosteróides.

Key words - Crohn's disease. Pleura. Pleural effusion. Corticosteroids.

\section{INTRODUÇÃO}

A retocolite ulcerativa $(\mathrm{Ru})$ e a doença de Crohn (DC) são doenças inflamatórias intestinais (Dii) que podem ou não estar associadas a manifestações extra-intestinais

* Trabalho realizado na Faculdade de Medicina do ABC (FMABC), Estado de São Paulo.

1. Professor Adjunto do Departamento de Pneumologia.

2. Mestre em Gastroenterologia pelo IBPG. Presidente da Sociedade Brasileira de Retocolite Ulcerativa e Doença de Crohn.

3. Residente do $2^{\circ}$ ano de Clínica Médica.

4. Aluna do $5^{\circ}$ ano.

Endereço para correspondência - Elie Fiss, Al. Santos, 705, cj. 32 01419-001 - São Paulo, SP, Brasil. Tel. (11) 3088-5568; fax (11) 285-2984; e-mail: eliefiss@uol.com.br

Recebido para publicação em 2/10/01. Aprovado, após revisão, em 4/6/02.
Siglas e abreviaturas utilizadas neste trabalho

DC - Doença de Crohn

$\mathrm{Ru}$ - Retocolite ulcerativa

Dii - Doença inflamatória intestinal

como artrite, uveíte, episclerite, eritema nodoso, pioderma gangrenoso e acometimento de vias aéreas ${ }^{(1,2)}$.

$\mathrm{O}$ acometimento pulmonar na $\mathrm{DC}$, especialmente $\mathrm{O}$ derrame pleural, é pouco freqüente $e^{(2)} e$ muitas vezes não diagnosticado, pois as manifestações respiratórias são geralmente interpretadas como outra doença não relacionada à doença inflamatória intestinal.

O objetivo deste relato de caso é mostrar uma manifestação rara da DC e estabelecer uma ligação entre atividade da DC e manifestações pulmonares.

\section{RELATO DO CASO}

Mulher branca de 34 anos, com diagnóstico de DC havia oito anos, procurou serviço médico apresentando febre e dor em região posterior do hemitórax esquerdo nos 
últimos três dias, negando tosse, dispnéia ou sintomas gastrointestinais. Uma semana antes da consulta, iniciou quadro de dores articulares generalizadas, sugerindo atividade da DC. Havia seis meses fora submetida à ressecção intestinal ( $30 \mathrm{~cm}$ de íleo e ceco) e fez uso de mesalazina $3 \mathrm{mg} / \mathrm{dia}$, interrompido três meses antes.

Paciente com $43 \mathrm{~kg}$ e $1,63 \mathrm{~m}$ de estatura, apresentavase ao exame físico com freqüência cardíaca de $100 \mathrm{bpm}$, pressão arterial de $120 \times 80 \mathrm{mmHg}$ e temperatura axilar de $38,5^{\circ} \mathrm{C}$. A ausculta cardíaca era normal, mas a pulmonar revelou murmúrio vesicular abolido em base de hemitórax esquerdo. $\mathrm{O}$ exame do abdome era normal. A radiografia de tórax mostrou derrame pleural posterior moderado, obliterando o seio costofrênico esquerdo. Os testes laboratoriais revelaram sinais de atividade inflamatória caracterizada por VHS $=45 \mathrm{~mm}$ (normal $=20 \mathrm{~mm}$ ) e PCR positivo. A paciente foi medicada com deflazacort $6 \mathrm{mg} /$ dia por cinco dias.

Os sintomas persistiram apesar do tratamento. Após revisão clínica do quadro e diagnóstico presuntivo de pneumonia, foi suspenso o uso do corticosteróide e introduzida levofloxacina $500 \mathrm{mg} /$ dia. Febre elevada $\left(39^{\circ} \mathrm{C}\right)$ e sinais clínicos de derrame pleural persistiram após sete dias de antibioticoterapia; uma nova radiografia de tórax revelou aumento do derrame pleural.

A paciente foi então internada para elucidação diagnóstica. A toracocentese identificou líquido pleural com $100 \%$ de linfócitos; a pesquisa de BAAR e fungos no líquido foi negativa. A biópsia pleural com agulha mostrou granuloma não-caseoso e a paciente passou a receber esquema tríplice para tuberculose, mas a febre $\left(38^{\circ} \mathrm{C}\right)$ e o derrame pleural residual persistiram após 20 dias de tratamento.

A hipótese de manifestação extra-intestinal da doença de Crohn foi então aventada; as drogas antituberculose foram suspensas e reintroduzida terapia com dose maior de deflazacort $(60 \mathrm{mg} / \mathrm{dia})$. Em apenas três dias de tratamento a febre cessou e a paciente referiu alívio da dor torácica. A melhora significativa do estado geral e diminuição progressiva do derrame pleural até seu completo desaparecimento colaboraram com a hipótese diagnóstica de atividade inflamatória da DC como causa do derrame pleural.

Não houve recidiva do quadro em 12 meses de acompanhamento.

\section{DISCUSSÃO}

As manifestações respiratórias associadas à Dii foram pela primeira vez descritas em 1976 por Kraft et al ${ }^{(2,3)}$ e podem ser classificadas em quatro grupos ${ }^{(2,4)}$ : doença das vias aéreas superiores; doença pulmonar intersticial; nódulo pulmonar parenquimatoso necrótico e serosite.
A serosite habitualmente é concomitante às manifestações intestinais ${ }^{(2)}$, fato que não foi verificado em nosso relato, em que a paciente não apresentava sintomas intestinais. O predomínio de linfócitos (100\%) no líquido pleural encontrado em nossa paciente difere do descrito na literatura (34 a 90\% de neutrófilos ${ }^{2}$ ).

Os sintomas respiratórios ocorrem freqüentemente logo após a realização da colectomia ${ }^{(2,5,6)}$, considerada fator de risco para desenvolvimento de doença pulmonar. Em nosso relato, o acometimento pulmonar ocorreu seis meses após a ressecção intestinal.

Os sintomas pulmonares também podem ser causados pelas drogas utilizadas para o tratamento da doença intestinal, como sulfassalazina ou mesalazina, sendo que a primeira droga pode levar a infiltrado pulmonar intersticial com eosinofilia periférica e a segunda droga não tem um padrão de acometimento definido(6). Entretanto, essa associação é pouco provável em nosso caso, visto que o uso da mesalazina foi interrompido três meses antes da ocorrência do derrame pleural.

A falta de resposta inicial ao deflazacort nesta paciente provavelmente foi conseqüência da dosagem insuficiente e curto tempo de tratamento, considerando-se que a dose de corticosteróide efetiva na fase ativa da DC é $1 \mathrm{mg} / \mathrm{kg} /$ dia de prednisona (ou equivalente), esperando-se boa resposta terapêutica a partir da segunda ou terceira semanas de tratamento.

Como a tuberculose tem prevalência muito maior que a DC, é comum a interpretação dos sintomas pulmonares como sendo tuberculose, justificando o uso de terapêutica antituberculose nestes pacientes. Puntis et al..$^{(7)}$ descreveram um caso de paciente com DC apresentando dor torácica, febre e nódulo pulmonar esquerdo tratado com antibiótico sem melhora, seguido de tratamento com corticosteróide em baixa dose; o esquema terapêutico para tuberculose foi iniciado devido à piora dos sintomas, sem sucesso. A remissão dos sintomas só ocorreu com a reintrodução de corticosteróide em doses mais altas.

A resposta terapêutica de nossa paciente quando utilizamos corticosteróides em doses realmente eficazes reforça a hipótese da natureza inflamatória da doença, visto que a corticoterapia tem sido considerada eficaz nos casos de envolvimento respiratório nas doenças inflamatórias intestinais ${ }^{(2,4)}$.

A apresentação clínica e laboratorial deste caso e sua evolução permitem-nos sugerir que pacientes com diagnóstico de doença de Crohn que apresentem manifestações pulmonares de etiologia não esclarecida devem ser investigados quanto a possível complicação pulmonar da doença intestinal. Essa suspeita deve ocorrer independente do tempo decorrido entre o início da doença intestinal e o aparecimento da sintomatologia pulmonar. 


\section{REFERÊNCIAS}

1. Levine JB, Lukawski-Trubish D. Extraintestinal considerations in inflammatory bowel disease. Gastroenterol Clin North Am 1995;24:633-46.

2. Camus P, Piard F, Ashcroft T, Gal AA, Colby TV. The lung in inflammatory bowel disease. Medicine 1993;72:151-83.

3. Camus P, Colby TV. The lung in inflammatory bowel disease. Eur Respir J 2000;15:5-10.

4. Kuzela L, Vavrecka A, Prikazska M, Drugda B, Hronec J, Senkova A, et al. Pulmonary complications in patients with inflammatory bowel disease. Hepatogastroenterology 1999;46:1714-9.
5. Bentur L, Lachter J, Koren I, Ben-Izhak O, Lavy A, Bentur Y, et al. Severe pulmonary disease in association with Crohn's disease in a 13year-old girl. Pediatr Pulmonol 2000;29:151-4.

6. Mahadeva R, Walsh G, Flower CD, Shneerson JM. Clinical and radiological characteristics of lung disease in inflammatory bowel disease. Eur Respir J 2000;15:41-8.

7. Puntis JWL, Tarlow MJ, Raafat F, Booth IW. Crohn's disease of the lung. Arch Dis Child 1990;65:1270-1. 